Background The role of polymorphonuclear cells in the development of a chronic inflammatory process still remains controversial. Neutrophilic granules comprise various biologically active proteins, which play a pathogenic role in the development of chronic auto-immune diseases, such as rheumatoid arthritis. Elastase - a marker of primary granules, being a factor of protection in healthy individuals, may exert a pro-inflammatory effect in rheumatoid arthritis, promoting the degradation of the cartilage matrix and the activation of proteolytic enzymes. The constituent of secondary neutrophilic granules - lactoferrin - a $77 \mathrm{kDa}$ protein with certain anti-microbal and anti-inflammatory properties.

Objectives To evaluate the role of constituents of neutrophilic granules ? lactoferrin and elastase ? in the pathogenesis of rheumatoid arthritis.

Methods In this study the serum levels of elastase and lactoferrin and an immunohistochemical staining reaction of polymorphonuclear cells for lactoferrin were assessed in 70 patients with rheumatoid arthritis.

Results The serum level of elastase - a marker of neutrophils' activation - was dramatically increased in patients with rheumatoid arthritis in comparison to healthy persons ( $p<0.001$ ). However, the serum level of lactoferrin was significantly decreased in patients with rheumatoid arthritis (195.5 \pm 11.7 $\mathrm{ng} / \mathrm{ml}$ vs. $626.9 \pm 20.8 \mathrm{ng} / \mathrm{ml}$ in healthy donors; $\mathrm{p}<0.001)$. Blood neutrophils displayed weak staining for lactoferrin in rheumatoid arthritis. The decrease of serum level of lactoferrin and its concentration in polymorphonuclear cells was greater in patients who were diagnosed with extra-articular manifestations, such as rheumatoid nodules and Felty's syndrome $(\mathrm{p}<0.05)$. These patients also had greater serum level of elastase. The serum level of lactoferrin didn't depend on the presence or absence of a rheumatoid factor or on the intensity of radiographic changes, but it inversely correlated with the serum levels of elastase, IgA, IgG, C-reactive protein and erythrocyte sedimentation rate. Treatment with non-steroidal anti-inflammatory drugs resulted in a clinical amelioration and was accompanied by the decrease of serum elastase level $(\mathrm{p}<0.01)$. The serum level of lactoferrin was slightly raised after treatment $(\mathrm{p}<0.05)$, which we consider to be a secondary effect due to decreased lactoferrin consumption. However, the intensity of neutrophilic staining reaction for lactoferrin remained unchanged.

Conclusion These data suggest a dysfunction of polymorphonuclear cells in rheumatoid arthritis: active synthesis and secretion of elastase is accompanied by the decreased synthesis of lactoferrin. The deficiency of lactoferrin - a potent antioxidant - may contribute to disease activity and the development of extra-articular manifestation in rheumatoid arthritis. The mechanism of this deficiency still remains unclear.

\section{THU0074 VITAMIN E UNCOUPLES JOINT INFLAMMATION AND ARTICULAR DESTRUCTION, IN A TRANSGENIC MOUSE MODEL OF RHEUMATOID ARTHRITIS}

${ }^{1} \mathrm{MJ}$ De Bandt, ${ }^{1} \mathrm{~F}$ Driss, ${ }^{1} \mathrm{M}$ Grossin, ${ }^{2} \mathrm{~J}$ Pincemail, ${ }^{1} \mathrm{C}$ Babin-Chevaye, ${ }^{3} \mathrm{C}$ Gaertner, ${ }^{1} \mathrm{C}$ Pasquier. IINSERM U 479, Bichat, Paris, France; ${ }^{2} \mathrm{CHU}$ de Liège, Domaine Du Start Tilman, Liège, Belgique; ${ }^{3}$ COGNIS, Dusseldorf, Deutschland

\subsection{6/annrheumdis-2001.951}

Background Reactive oxygen species (ROS) are suspected to play a role in human RA. Transient hypoxia and ischaemic-reperfusion phenomenon are involved in their chronic production, by monocytes and macrophages. Nevertheless the clinical interest of ROS scavengers is difficult to evaluate.

Objectives

Methods We studied the effects of Vitamin E (natural alpha tocopherol) on transgenic KRN/NOD mice, new model for rheumatoid arthritis. We determined clinical, histological and biochemical parameters so as to define the long-term benefit of Vitamin E in the disease.

Results We found an increase in plasma Vit E, in treated mice. Vitamin $\mathrm{E}$ treatment did not modify the date of onset of the disease, neither the intensity of the disease (arthritic index and weight), but Vit-E prevented from articular destruction, suggesting uncoupling of the two phenomenon. Biochemical analysis, blood glutathion, urine isoprostane and the plasma hydroperoxide did not differ between Vit E-treated transgenic KRN/NOD mice and control mice. Blood chemiluminescence was increased in transgenic KRN/NOD mice as compared to non-transgenic mice, and was decreased in Vit E-treated transgenic KRN/NOD mice. TNF-a and IL1-b, low in control non-transgenic mice, were increased in transgenic KRN/NOD mice, however a significant decreased in IL-1b appeared in Vit E-treated mice.

Conclusion These results suggest that ROS scavengers can modulate cytokines responses and provide new arguments for the interest of ROS scavengers in RA therapy.

\section{THU0075 MYCOPLASMA PNEUMONIAE INFECTION AND RHEUMATOID ARTHRITIS}

AS Ramirez-Corbera, JA Hernández-Beriain, A Rosas, E Girona. Rheumatology Section, Hospital Insular de GC, Las Palmas de GC, Spain

10.1136/annrheumdis-2001.952

Background An infective aetiology for rheumatoid arthritis (RA) has often been postulated. Thirteen species of mycoplasmas has been implicated in the origin of arthritis in experimental models and animals. Fragments of mycoplasma (PCR) has been detected in RA although the results are conflictive.

Objectives The main of our work is to evaluate previous mycoplasma pneumoniae (MP) infection in a cohort of RA outpatients and further evaluation of MP infection and RA outcome.

Methods In 80 RA patients IgG antiMP was evaluated with ELISA. RA was evaluated according to disease duration, RF status and radiological stage. In control group were included 150 healthy people. Statistical analysis included Kruskal-Wallis test for IgG levels and determination of relative risk (odds ratio).

Results Mean age of RA patients was 53.17 (22-81 years); 83\% were females. MP serology was positive in 54\% of RA patients and $31 \%$ of controls $(\mathrm{p}<0.05)$. Medium level of IgG was 1.431 in RA patients and 0.87 in controls $(\mathrm{p}<0.0001)$. Previous MP infection conditioned a relative risk (odds ratio) for RA of 3.22 (95 CI; 1.76-5.91).

Conclusion Previous MP infection was more frequent in RA patients than controls. MP infection could play a role in RA genesis. 